apparent absence of an acidity anomaly for the Waimihia eruption (dated at $\sim 3,800$ yr BP (ref. 11)), we note that the Greenland ice-core study ${ }^{12}$, from the period 3,050-4,650 yr BP, considered only acidity levels greater than $2.6 \mu$ equiv $\mathrm{H}^{+}$per $\mathrm{kg}$ of ice. As the far larger Northern Hemisphere eruptions of Santorini and Mt Mazama only produced acidity signals of 5.3 and $6.0 \mu$ equiv $\mathrm{H}^{+}$per $\mathrm{kg}$ of ice, respectively, then the absence of a marked peak attributable to the Waimihia eruption is not significant. The dispersal of its deposits, moreover, implies that the Waimihia eruption was appreciably less powerful than the Taupo eruption.

(5) Froggatt summarily dismisses the historical evidence and concludes that the observed phenomena were possibly the results of fires or dust storms. However, internal evidence suggests that none of these alternatives seems likely, although the probability of one of the early writers describing the effects of a supernova ${ }^{13}$ cannot be ruled out.

In conclusion, none of Froggatt's objections invalidate the grounds on which we proposed a correlation between the Taupo eruption and the optical effects observed in $\sim$ AD 186 in both China and Rome.

\section{Geology Department,}

$$
\text { C. J. N. WilsoN }
$$

University of Auckland,

Private Bag,

Auckland, New Zealand

\section{N. N. AMBRASEYS}

Civil Engineering Department,

Imperial College,

London SW7 $2 B U$, UK

\section{J. BRADLEY}

18 Juniper Lane,

Amherst,

Massachusetts 01002, USA

G. P. L. WALKER

Department of Geology and Geophysics, University of Hawaii, 2525 Correa Road,

Honolulu,

Hawaii 96822, USA

1. Wilson, C. J. N., Ambraseys, N. N., Bradley, J. \& Walker, G. P. L. Nature 288, 252-253 (1980).

2. Mossop, S. C. Nature 203, 824-827 (1964).

3. Kohn, B. P. \& Glasby, G. P. N.Z. J. Geol. Geophys. 21 49-70 (1978)

4. Lewis, K. B. \& Kohn, B. P. N.Z. J. Geol Geophys. 16, 439-454 (1973).

5. Watkins, N. D. \& Huang, T. C. N.Z. J. Geol. Geophys. 20, 179-198 (1977).

6. Ninkovich, D. \& Heezen, B. C. Colston Res. Pa. 17 $413-452$ (1965).

7. Watkins, N. D. Earth planet. Sci. Lett. 4, 341-349 (1968)

8. Walker, G. P. L. J. Volcanol. geotherm. Res. 8, 69-94 (1980).

9. Lamb, H. H. Phil. Trans. R. Soc. A266, 425-533 (1970)

10. Zen, M. T. \& Hadikusumo, D. Bull. Volcanol, 27, 269-299 (1964).

11. Rampino, M. R., Self, S. \& Fairbridge, R. W. Science 206, 826-829 (1979).

12. Hammer, C. U., Clausen, H. B. \& Dansgaard, W. Nature 288, 230-235 (1980).

13. Stothers, R. Isis $68,443-447$ (1977)

\title{
Does mate choice occur in Drosophila melanogaster?
}

PARTRIDGE ${ }^{1}$ recently reported the results of a series of experiments purporting to demonstrate that "... one component of offspring fitness can be increased by mate choice in Drosophila melanogaster". Her experiments involved the mating of females to single males and to a choice of males. The data show a significant difference in the competitive ability of offspring from choice mating when compared with those from nochoice matings $(P<0.02)$.

Her paper, entitled "Mate choice increases a component of offspring fitness in fruit flies", implies a conclusive result but she admits that the results can be interpreted in two ways. First, individual females "... could then mate with a fly that was successful in some sort of competition with members of its own sex". We believe that Partridge must recognize that the occurrence of malemale competition could mask any possible choice by females. Her second alternative is that "flies may be able to detect heritable fitness in members of the other sex". The choosing by females of 'fit' males is commonly referred to as mate choice or female choice ${ }^{2,3}$.

The problem lies in Partridge's central question: "Does mate choice increase a component of fitness (competitive ability of larvae) in Drosophila melanogaster?". This question is, by definition, composed of two parts: (1) does mate choice occur? and (2) how does this affect offspring fitness? Part (1) must be demonstrated before any conclusions can be drawn relating offspring fitness to mate choice.

Partridge has demonstrated that either adult males that are more successful in male-male competition have larval offspring which are better competitors (heritability of a fitness component), or that mate choice by females of maximally fit males occurs. As her experiments were not designed in such a way as to distinguish between the two alternatives of male-male competition and mate choice, we believe that she has not justified her claim that mate choice is occurring in D. melanogaster.

P. D. KINGETT

D. M. LAMBERT

Department of Zoology,

University of Auckland,

Private Bag, Auckland, New Zealand

\section{S. R. TELFORD}

Department of Zoology,

University of the Witwatersrand,

Jan Smuts Avenue,

Johannesburg 2001, South Africa

1. Partridge, L. Nature 283, 290 (1980),

2. Trivers, R. L. in Sexual Selection and the Descent of Man (ed. Campbell, B.) 136-179 (Aldine-Atherton, Chicago, 1972)

3. Krebs, J. R. \& Davies, N. B. Behavioural Ecology (Blackwell, Oxford, 1978)
PARTRIDGE REPLIES-The central cri ticism by Kingett et al. is that they say I stated $^{1}$ that female choice of males as mates must be responsible for my results. In reply, I quote the last paragraph of my paper: "The result could be produced by various genetic mechanisms. First, fitness may indeed be heritable, possibly as a consequence of mutational load. If this were the case, the results could be produced in two ways. (1) Fitter flies may be better at detecting or obtaining access to mates. Members of the other sex could then mate with a fly that was successful in some sort of competition with members of its own sex. (2) Flies may be able to detect heritable fitness in members of the other sex. Fitter flies could then be actively chosen as mates. Both possibilities would suggest that all flies should prefer the same sorts of mates. Alternatively, flies with high levels of heterozygosity may have high fitness. In this case, flies might produce fitter offspring by mating with individuals genetically unlike themselves, so that their offspring will have higher levels of heterozygosity. This last possibility would imply that genetically dissimilar flies would show different patterns of mate choice".

Possibility (1) encompasses the alternative suggestion of Kingett et al. that inter-male competition could be responsible for my results. In their final paragraph, Kingett et al. state that my results must be produced by heritable fitness variation in males. This is not necessarily true, as my final suggestion in the above quotation makes clear.

I used the term 'mate choice' in the title and introduction of my paper to avoid the cumbersome alternative 'The opportunity to mate non-randomly increases a component of offspring fitness in fruit flies' which is what my results demonstrate.

\section{PARTRIDGE}

Department of Zoology,

University of Edinburgh,

West Mains Rd, Edinburgh EH9 3JT, UK

1. Partridge, L. Nature 283, 290 (1980).

\section{Matters Arising}

Matters Arising is meant as a vehicle for comment and discussion about papers that appear in Nature. The originator of a Matters Arising contribution should initially send his manuscript to the author of the original paper and both parties should, wherever possible, agree on what is to be submitted. Neither contribution nor reply (if one is necessary) should be longer than 300 words and the briefest of replies, to the effect that a point is taken, should be considered. 